\title{
Sobre la Historia POLÍtica Y LA VUELTA dEL ESTADO ${ }^{1}$
}

\section{Juan Sisinio PÉREZ GARZÓN \\ Universidad de Castilla-La Mancha}

En la obra de Javier Donézar hay una constante: sus investigaciones se han situado siempre por encima de modas historiográficas y de esos compartimentos estancos de las especialidades académicas. Como historiador nos ha enseñando que nunca un campo historiográfico tiene que expandirse a expensas de otros espacios de investigación como si hubiera un reparto de zonas de influencia entre especialidades o por edades históricas. De hecho, sus estudios rompen casi todos ellos las lindes académicas establecidas entre la Edad Moderna y la Contemporánea; también rompen las fronteras establecidas entre lo que catalogamos como historia agraria, historia social, historia institucional, historia de las ideologías, historia nacional o historia local. Sus investigaciones pueden encajarse perfectamente en una o varias de estas especialidades a la vez, por abordar temas que se ajustan tanto a historia social como a historia agraria o también a historia institucional y, en todo caso, a la historia nacional, aunque sea desde espacios concretos de localidades tan decisivas como, por ejemplo, Toledo.

Ahora bien, a mi entender, en todas sus obras hay una preocupación metodológica permanente, la explicación política de los hechos, procesos o ideas que en cada caso Javier Donézar investiga de forma rigurosa y sólidamente documentada ¿Por qué esa constante del factor político como condicionante que mediaba los hechos históricos? Precisamente porque siempre mantuvo la perspectiva de lo político como expresión de los procesos sociales, económicos y culturales. De este modo, esas modas que implicaban la hegemonía de una u otra especialidad, de un método u otro, en la obra de J. Donézar quedan integradas dentro de una preocupación profundamente humanista por desentrañar las relaciones entre los factores que explican cada momento histórico. En

\footnotetext{
${ }^{1}$ Se toma la expresión de T. SKOCPOL, "El Estado regresa al primer plano: estrategias de análisis en la investigación actual", en Zona Abierta, $n^{\circ}$ 50, 1989, pp. 71-122 (ed. en inglés de 1985).
} 
consecuencia, en su obra la variable política siempre aparece como factor explicativo necesario. Es más, en muchos de sus trabajos es el propio objeto de estudio. Esto se constata de modo muy destacable en las importantes tesis que ha dirigido sobre cuestiones tan decisivas como el catastro de 1906, las política hidráulica en la Restauración, la política vitivinícola, la propiedad en el Antiguo Régimen, sus desamortizaciones y repartos, el carlismo, la disolución de los jesuitas en España o figuras emblemáticas de la historia cultural y política como el cardenal Borbón y el periodista Fermín Caballero. La dirección de tesis tan destacables es otra dimensión del magisterio de J. Donézar que es justo subrayar como prolongación de la actividad docente en su nivel más superior.

Por lo demás, otra constante de los estudios realizados por Javier Donézar, así como de las investigaciones que ha dirigido, radica en su orientación hacia la interdisciplinariedad metodológica. Ha usado recursos de la historia cuantitativa para darle anclajes empíricos a los análisis cualitativos, pues no concibe lo estructural y lo coyuntural, lo individual y lo colectivo o los datos locales y los procesos generales como cuestiones opuestas entre sí. Al contrario, lo individual, lo concreto, lo local y lo coyuntural son parte de esa dialéctica compleja por la que interactúan recíprocamente dentro de aquellos procesos estructurales que permiten explicar la andadura general de la historia en cada momento. Por todo esto, esbozar algunas reflexiones sobre el valor de la política en la explicación de los procesos históricas y recordar someramente el actual panorama historiográfico al respecto puede ser un justo modo de homenajear la obra investigadora y la tarea de formación de historiadores desarrollada por el profesor Javier Donézar.

\section{1.- Persistencia de la historia política: el impulso de la politología.}

Hoy resulta evidente que, más allá de la fórmula propagandística, no hubo retorno de la historia política a partir de los años 80 y 90 del siglo XX, porque aquella tradicional metodología historicista, con predominio absoluto del hecho político, nunca había desaparecido. Al contrario, hubo medios universitarios y países donde la historia del devenir político, de sus aconteceres y personajes siguieron dominando. Ahora bien, es cierto que el avance de la politología como ciencia y de las subespecialidades en la historia, desde los años sesenta, así como la quiebra profesional de esa aspiración a una historia total en los años ochenta, fueron los factores que permitieron airear la necesidad de renovar la historia política. Tampoco hay que olvidar un dato imprescindible, el 
creciente peso de los Estados en todos los órdenes del devenir social, así como el enorme potencial que despliegan desde los años setenta los medios de comunicación en la difusión de las noticias sobre todo tipo de eventos.

Sin tal contexto no se comprende el renovado impulso que recibe eso que coloquialmente se califica como "vida política" o lo "político". Desde tales estímulos se acometió la revitalización de métodos y técnicas de investigación en la historia política, dándole además el rango de especialidad frente a otras tantas que se hacían pasar por más actualizadas o modernizadas. En este sentido, la reorganización teórica y metodológica de la especialidad de historia política provino de distintos frentes, desde la sólida tradición marxista hasta los influjos de las nuevas teorías en politología.

Es justo, no obstante, recordar que mientras la historia política se retraía ante el avance de las historias económicas y sociales, de los métodos estructurales y de las técnicas cuantitativas durante las décadas centrales del siglo XX, no por eso quedaba en el olvido el análisis de los factores políticos, sobre todo porque crecía a lo largo del siglo XX una nueva disciplina, la politología, en especial en el ámbito anglosajón. Habría que remontarse, sin duda, al cambio del siglo XIX al XX cuando, por un lado, en 1895 se inauguró por los intelectuales fabianos la London School con el fin de enseñar economía y ciencia política, y, por otro, en 1903, se creaba en los Estados Unidos la American Political Science Association (APSA) que en 1994 alcanzaba los 13.000 miembros de setenta países ${ }^{2}$. Posteriormente, en 1950 se fundaba en Gran Bretaña el Political Studies Association of the United Kingdom, que mantiene una amplia red de miembros. Por otra parte, en 1970 se organizó el Consorcio Europeo para la Investigación Política (European Consortium for Political Research, ECPR) con ocho miembros y a mediados de los noventa lo integraban doscientas instituciones.

Así, a lo largo del siglo XX se fragua esa nueva disciplina que hoy se define como ciencia política, y que ya en los años sesenta estaba suficientemente madura como para plantearse nuevos derroteros. A eso trató de responder la obra de W. J. Mackenzie, quien en 1967 publicaba Political and Social Science no sólo como balance de los estudios académicos de la política, sino como propuesta de renovación de una disciplina que definía como científica y que tenía, por tanto, que abrirse a nuevos campos como el

\footnotetext{
${ }^{2}$ Existe el precedente de L'École Libre des Sciences Politiques, de 1872, pero los primeros clásicos de la ciencia política aparecen en Estados Unidos, aunque bajo influencia europea, ver Klaus von BEYME, Teorías políticas contemporáneas, Madrid, IEP, 1977.
} 
de los estudios de la conducta y las técnicas cuantitativas, en sintonía con el resto de las ciencias sociales ${ }^{3}$. Analizaba las aportaciones del marxismo, la teoría de sistemas, la teoría de juegos y el enfoque económico al estudio de la política, para exigir la introducción también de las ideas procedentes de la biología y de la psicología social. Eran los años en que la ciencia política se desgajaba definitivamente como disciplina propia y dejaba de ser un apartado de la teoría filosófica del Estado o del derecho público o de la historia general. Se convertía en la ciencia del estudio de las relaciones entre el poder político y la sociedad, del subsiguiente comportamiento político y de las teorías e ideologías referidas a la dominación y a la praxis política, un perfil en el que fueron decisivas las aportaciones de europeos como Duverger y Abendroth ${ }^{4}$.

El desarrollo de la ciencia política ampliaba, por tanto, su área de estudio, sin abandonar ese campo tradicional de las instituciones -el parlamento y la administración pública-, que también se abría hacia los análisis electorales, los partidos políticos de masas y los grupos de presión. La producción científica al respecto ha sido tan abundante desde los años setenta que, por supuesto, no es posible hablar de historia de la historiografía sin tener en cuenta las aportaciones de la politología por lo que ha significado para lo que se consdiera el resurgir de la política en la ciencia histórica ${ }^{5}$.

Por otra parte, es necesario reiterar que la historia política nunca desapareció del escenario historiográfico. Al contrario, en Alemania, por ejemplo, la historia política hizo de cauce para integrar y promover las aportaciones de la historia social. Así, el debate sobre el nazismo y sus apoyos sociales fue un buen ejemplo al respecto ${ }^{6}$. También ocurrió en España desde los años setenta cuando se solaparon debates en los los factores políticos fueron al unísono con los análisis sociales, como ocurrió en el debate sobre la revolución burguesa o sobre la industrialización, por citar dos ejemplos bien claros a este respecto, o luego el prolongado debate sobre la guerra civil. Cabe recordar y subrayar que en la historiografía española, desde los años setenta, la historia política estuvo en el primer plano en aquel núcleo de renovación de los Coloquios de

\footnotetext{
3 W. MACKENZIE, Política y ciencia social, Madrid, Aguilar, 1973.

${ }^{4}$ Ver el clásico W. ABENDROTH y K. LENK, Introducción a la ciencia política, Barcelona, Anagrama, 1968. Estos autores impulsaron en los años sesenta una concepción de la ciencia política como "ciencia histórica de la sociedad", mientras Maurice DUVERGER la definía como "ciencia del poder", en Sociología política, Barcelona, Ariel, 1972.

${ }^{5}$ Para un estado clásico de la cuestión en la politología, ver David MARSH y Gerry STOKER, eds., Teoría y métodos de la ciencia política, Madrid, Alianza, 1997.

${ }^{6}$ Baste citar G. ELEY, "Nazism, politics and the image of the past: thoughts on the West German Historikerstreit, 1986-1987", en Past and Present, no 121, 1988, pp. 171-208.
} 
Pau, organizados por Tuñón de Lara. Además, la realidad de una dictadura y de la transición a la democracia situaron obligatoriamente lo político en el primer plano de la producción historiográfica ${ }^{7}$. Tampoco conviene olvidar que incluso en el seno de los Annales, el propio cofundador del grupo, Marc Bloch, publicó en 1924 Les Rois Thaumaturges, una obra de clara filiación con la historia política, bien que renovada. A eso se sumaría luego Braudel para quien "la historia política no es forzosamente la historia de los acontecimientos, ni está condenada a serlo" ${ }^{8}$.

En efecto, los debates de historia política no habían desaparecido de la disciplina por más que se repita el tópico de que había quedado marginada como especialidad o área de preferente investigación. Además de los citados para Alemania o España, también los hubo en otros países, como en Italia sobre el liberalismo giolittiano o sobre el fascismo, o en Gran Bretaña sobre múltiples cuestiones de su pasado, porque en este país su historiografía contaba con una excelente nómina de historiadores de la política, con nombres como los de H. Trevor-Roper, Edward H. Carr, A.J.P. Taylor o Allan Bullock ${ }^{9}$. En todos los casos se evidenciaba que la historia política ya no podía acantonarse en aquellos detalles y minucias de la historia "évenementielle", sino que afrontaba el reto de integrar en sus análisis el estudio de los lenguajes políticos, de las culturas políticas y también de esos aspectos que son rituales en la vida política. Y no sólo en el nivel de los líderes, sino también y sobre todo en sus dimensiones sociológicas anónimas o populares, de masas. Además se produjo desde los años sesenta del siglo XX una ósmosis bastante permanente entre historiadores sociales e historiadores políticos, quizás las dos áreas con mayor fluidez de relación.

\section{2.- ¿Retorno o revitalización?}

\footnotetext{
${ }^{7}$ Para corroborar tal aserto, ver para los años setenta y ochenta del pasado siglo XX los siguientes balances que ya testimonian el interés por la historia política: M. TUÑÓN DE LARA, ed., Historiografía contemporánea. X Coloquio de Pau, Madrid, Siglo XXI, 1980; G. RUEDA, ed., Doce estudios de historiografía contemporánea, Santander, Universidad de Cantabria, 1991; J. TUSELL, "El sufragio universal en España (1891-1936): un balance historiográfico", Ayer, no 3, 1991, pp. 13-62; J. AVILÉS FARRÉ y J. GIL PECHARROMÁN, "El cincuentenario de la Guerra Civil. Un comentario bibliográfico", en Historia Social, no 5, 1989, pp. 147-155. Posteriormente se ha seguido en esta senda con numerosas investigaciones de calidad y con los correspondientes balances historiográficos cuya enumeración rebasa el objetivo de estas páginas.

${ }^{8}$ F. BRAUDEL, Escritos sobre historia, México, FCE, 1991 ( ed. or. 1969), p. 35.

9 Para Italia, ver L. DE ROSA, ed., La storiografia italiana degli ultimi vent'anni, III, Etá Contemporanea, Bari, Laterza, 1993; y R. DE FELICE, Roio y negro, Barcelona, Ariel, 1996; y para otros debates, ver R.W. FOGEL y G. ELTON, ¿Cuál de los caminos al pasado? Dos visiones de la Historia, México: FCE, 1989. En el caso británico la bibliografía es abundante, pero baste citar F.M.L. THONTSON (dir), The Cambridge Social History of Britain, 1750-1950, 3 vols., Cambridge, 1990.
} 
En el citado contexto se produjo la irrupción de lo que se llamó "nueva historia política", desde cauces que no fueron ni homogéneos ni coincidentes. Esta "nueva historia política" más bien fue una revitalización con la sabia nueva de la politología, por un lado, y de la historia social y cultural, por otro. Es cierto que los que a sí mismos se consideraron innovadores tuvieron que perfilar un enemigo contra el que luchar y frente al cual definir la identidad de esta "nueva historia política". Así hay que entender la polémica contribución de J. Julliard, a comienzos de los setenta ${ }^{10}$, cuando denostó la vieja historia política por dedicarse sobre todo a los grandes personajes y estar desligada de las masas. En ese mismo sentido actuó Pierre Balmand quien esquematizó el panorama intelectual dominante en las ciencias sociales durante los años cincuenta y sesenta, reduciéndolo a la historia serial, de ciclos económicos y de grandes procesos estructurales, "contraria a una historia política, todavía acusada de decantarse sospechosamente hacia los acontecimientos", para proponer como alternativa un cambio de paradigma que significase el "retorno de la conciencia y la rehabilitación de la parte explícita y reflexionada de la acción". ${ }^{11}$

En la estela de R. Rémond, ensalzaba la tarea renovadora emprendida por los historiadores de estas corrientes proponiendo, a su vez, que "la nueva historia política" era la auténtica protagonista de la “completa mutación” en el paradigma historiográfico, de modo que sabía hacerse cuantitativa en el momento necesario, estaba igualmente "atenta al acontecimiento, pero también a los movimientos de gran amplitud (las ideologías de larga duración, por ejemplo) y a las estructuras, especialmente a través de la noción de cultura política". De este modo, para Balmand, "la nueva historia de lo político satisface actualmente las principales aspiraciones que habían suscitado la justificada rebelión contra la historia política tradicional. Abrazando decididamente los grandes nombres, trabajando a base de ciclos de larga duración, aprehendiendo los fenómenos más globales, investigando en las profundidades de la memoria colectiva o del inconsciente las raíces de las convicciones y los orígenes de los comportamientos la historia política ha hecho una revolución completa. Al tratar de aprehender todas las

\footnotetext{
${ }^{10}$ J. JULLIARD, "La política", en J. LE GOFF et alii, Hacer la historia, Barcelona, Laia, 1979 (ed. or. de 1974).

${ }^{11}$ P. BALMAND, "La renovación de la historia política", en Bourdé, G. y Martín, H.: Las escuelas históricas, Madrid, Akal, 1992, pág. 257.
} 
facetas de la realidad colectiva ¿no se ha convertido la historia con esta actitud, en una forma de historia total?". ${ }^{12}$

Tanto optimismo chocó, sin embargo, con la realidad de unas investigaciones que lógicamente no alcanzaban a cumplir tales objetivos. De hecho Balmand dejaba al descubierto la ambigüedad de sus postulados cuando afirmaba que "no se concibe lo estructural y lo coyuntural, el ciclo largo -o el medio- y los acontecimientos como términos antinómicos, sino más bien como los dos polos de una dialéctica compleja, por la que actúan recíprocamente, mediante los fenómenos de la memoria, estructura y coyuntura, cada una sobre la otra". ${ }^{13}$ ¿Se trataba de postulados ambiguos para rechazar el determinismo? Desde luego resultaban insuficientes porque, al final, según el padre de esa renovación, el propio René Rémond argumentaba que la explicación de lo político, el nuevo paradigma tenía que centrarse en la búsqueda de "las profundidades de la memoria colectiva o del inconsciente, de las raíces de las convicciones y los orígenes de los comportamientos"14. Por eso, esa recuperación de lo mental y de las filosofías de la conciencia desplazaba la explicación histórica desde las condiciones objetivas a propuestas que incluso podían alcanzar al subconsciente

Mientras tanto, en los Estados Unidos el cuantitativismo extendía su dominio a la historia política. La New Political History recogía el triunfo de la new economic history y así entraban en los análisis políticos las ecuaciones de regresión, las curvas de distribución y los elementos del análisis factorial. Trataban, en definitiva, de darle soporte a una historai estrucural y social, propuesta dominante en ese momento, y por eso la mayoría de sus investigaciones se publicaron en revistas como The Journal of Interdisciplinary History, o en la Social Science History. Los nuevos campos de estos historiadores ya no eran los tradicionales, sino el estudio de fenómenos electorales, la biografía colectiva de políticos, el estudio de instituciones parlamentarias, aunque, es cierto, había precedentes al respecto.

La novedad incuestionable consistía en la introducción de los métodos de la sociología electoral en la historiografía, si bien esto implicaba que las fuentes sólo eran fiables a partir de la implantación del sufragio universal. Entre las obras que hicieron época en el estudio de las actitudes y de los comportamientos políticos colectivos, hay que recordar

\footnotetext{
${ }^{12}$ P. Balmand, op. cit. supra, pp. 257-258. Hay que recordar que el texto de Balmand está construido sobre frases de Rémond.

${ }^{13}$ P. Balmand, op.cit. supra, pág. 264.

${ }^{14}$ R. RÉMOND, Pour une histoire politique, Paris, Ed. du Seuil, 1988.
} 
los estudios de Rae, en 1967, que investigó 115 elecciones en veinte países, utilizando las instituciones y no los individuos, como unidad de análisis, luego ampliados por Powell, o los de McClosky sobre las actitudes de las élites hacia los derechos humanos en los Estados Unidos, sin olvidar en Gran Bretaña las investigaciones de Butler y Stokes, de 1969, sobre la evolución del componente de clase en la política británica, cuantificando a los miembros de esas elites ${ }^{15}$. Se articuló de este modo una politología retrospectiva que, por lo demás, experimentó la misma deriva que su pariente la cliometría económica, esto es, el anacronismo y la atemporalidad de sus análisis ${ }^{16}$.

En este sentido, conviene insistir en que la revitalización de la historia política tuvo más endeudamiento del que se reconoce con la politología, porque esta ciencia se desplegó desde los años setenta y ochenta del pasado siglo XX con importantes renovaciones sobre el institucionalismo e incorporando además las perspectivas del análisis conductista, de la teoría de la elección racional, la perspectiva feminista y la teoría del discurso ${ }^{17}$. Es justo subrayar cómo se produjo una importante convergencia desde metodologías marxistas, linguísticas y feministas para situar los procesos políticos en el centro de la comprensión de las relaciones sociales y en la subsiguiente transformación histórica, porque se conciben tales procesos como conflictos y luchas entre fuerzas antagónicas que pretenden estructurar el significado de la sociedad ${ }^{18}$.

En ese orden de cosas, procede igualmente destacar el peso de la obra de Michel Foucault porque descentralizó radicalmente el concepto de poder al definirlo como ese entramado de relaciones de fuerza distribuidas con carácter asimétrico en una sociedad, y que abarcan no sólo el poder político clásico sino también el poder del sexo, del afecto o de la ciencia y de la inteligencia. Con Foucault se expandió como premisa la formulación del feminismo radical norteamericano de Kate Millet de que "todo lo

\footnotetext{
${ }^{15}$ Ver las obras de D. RAE, The Political Consequences of Electoral Laws, Londres, Yale University Press, 1967; G. B. POWELL, Contemporary Democracies: Participation, Stability and Violence, Londres, Harvard University Press, 1982; H. McCLOSKY y A. BRIL, Dimensions of tolerance: What Americans Believe About Civil Liberties, nueva York, Russell Sage, 1983; D. E. BUTLER y D. STOKES, Political Change in Britain, Londres, Macmillan, 1974.

${ }^{16}$ Para la cuantificación en la historia política: D.K. ROKY y J.Q. GRAHAM, eds., Quantitative History (Selected Readines in the Quantitative Analysis of Historical Data), Homewood, Dorsey Press, 1969; y J. W. SCOTT, "History in Crisis? The Other 's Side of the Story", American Historical Review, vol. 94, 1989, pp. 680-692.

${ }^{17}$ Sobre el nuevo institucionalismo, J. G. MARCH y J. P. OLSEN, "The New Institutionalism: Organisational Factors in Political Life", American Political Science Review, 78, pp. 734-49; y de J. G. MARCH y H. A. SIMON, Teoría de la organización, Barcelona, Ariel, 1994.

${ }^{18}$ La obra de Ernest LACLAU y Chantal MOUFFE, Hegemonía y estrategia socialista: hacia una radicalización de la democracia, Madrid, Siglo XXI, 1987 (ed. or. de 1985) rompe al reivindicar una interpretación lingüística de la realidad social, por un lado, y, por otro, abandonar la lógica clasista marxista para impulsar un modelo alternativo de sociedad democrática.
} 
personal es político"19 , porque, en efecto, no hay nada personal ajeno a las relaciones de poder que construyen y ahorman las redes sociales y mentales con que vivimos y percibimos la cotidianeidad. Fue una ampliación del ámbito de la política que iba más allá de su definición cívico-normativa y restrictiva, y esto ha repercutido en las nuevas historiografías de género o del sexo y de la ciencia, por ejemplo.

Así, desde los años 80 del siglo XX se extendió la potencialidad explicativa de la historia política. Baste citar, a título de ejemplos, los nuevos análisis sobre el imperialismo, incluyendo factores no económicos como las rivalidades políticas por el control territorial, o sobre el fascismo, relacionando evolución del paro, progresión nazi e incapacidad de otros partidos ${ }^{20}$. Se discute, en definitiva, el viejo y clásico problema del Estado y su significado, pero el énfasis en recuperar la historia política no se hace para privilegiar las interpretaciones de índole política a costa del resto de factores, aunque es cierto que no debe ocultarse que tras las alharacas revitalizadoras de la historia política se esconde a veces un nuevo intento de parcelación historiográfica claramente conservadora, como ocurre con las interpretaciones de R. Cobban o F. Furet sobre la revolución francesa, que ocultan la realidad de los movimientos sociales.

\section{3.- Entre las aportaciones weberianas y la tradición marxista}

Sin duda, los análisis enraizados en la tradición weberiana y los procedentes de esa otra tradición marxista que Gramsci rescató del determinismo económico han sido determinantes para la renovación de la historia política. Max Weber, en concreto, introdujo el concepto de legitimación. Legitimación que no era sino la aceptación por los súbditos del poder político, pero también significaba la imposición misma de ese poder desde arriba. Era el concepto clave para comprender la capacidad del Estado para establecer una relación duradera y estable de dominación política sobre la sociedad civil, pues, impuesta y aceptada a la vez, hacía posible la dominación. Weber situó así el análisis del poder como convergencia de los conflictos de intereses en el proceso de racionalización de una sociedad ${ }^{21}$. No era el simple reflejo de los intereses económicos como pensaban bastantes liberales del momento o los marxistas de la segunda Internacional.

\footnotetext{
${ }^{19}$ Kate MILLET, Política sexual, Madrid, ed. Cátedra, 2010 (ed. original en inglés, 1970)

${ }^{20}$ D.K. FIELDHOUSE, Economía e imperio: la expansión de Europa. 1830-1914, Madrid: Siglo XXI, 1986; K.D. BRACHER, Controversias de historia contemporánea sobre fascismo, totalitarismo y democracia, Barcelona, Alfa, 1983; C. KLEIN, Del espartaquismo al nazismo, La República de Weimar, Madrid, 1985.

${ }^{21}$ A. GIDDENS, Política y sociología en el pensamiento de Max Weber, Madrid, Alianza, 1976.
} 
Simultáneamente, en esos años, aunque su obra trascendería más tarde, Gramsci perfiló el concepto de hegemonía con el que, frente a sus colegas del marxismo economicista, otorgó a la política y al Estado un funcionamiento bastante independiente con respecto a la infraestructura económica. El concepto de hegemonía permite, sin duda, conocer los mecanismos y resortes propios del poder pero sobre todo la peculiaridad de las instituciones, las formas de conciencia y las creencias ideológicas a través de las cuales se expresa el poder de una clase social.

Es justo la hegemonía de una clase social la que se manifiesta en esa identificación entre "sociedad política" y "sociedad civil" donde el concepto de Estado ya es bastante más que la pura coerción, pues no se mantiene si no es por ese consenso logrado a través precisamente de la hegemonía de esa clase social que lo soporta. Las ideologías, por tanto, dejaron de ser para Gramsci aquel espejo deformado y deformante de la realidad que pensaba la mayoría de los ortodoxos marxistas ${ }^{22}$. Por eso, cuando en los años cincuenta y sesenta, se rescató el pensamiento de Gramsci, el fortalecimiento del Estado de bienestar ayudó también a reutilizar la obra del pensador italiano para revisar la anquilosada ortodoxia marxista y enfocar el papel de las instituciones con nuevos instrumentos de análisis. No fue casualidad, por tanto, el carácter innovador del marxismo británico de los años cincuenta y sesenta del pasado siglo $\mathrm{XX}^{23}$.

En suma, se depuraron los instrumentos de análisis, se echó mano de la sociología política y se cambió el rumbo de la historia política. Ya no eran los eventos diplomáticos y bélicos, sino que las investigaciones abordaron la organización institucional y la acción interior que el Estado desplegaba en la sociedad para mediar entre los intereses de los grupos sociales y el acceso al poder. Aparecieron así los partidos políticos como objetos prioritarios de análisis porque los partidos, en sentido gramsciano, son bastante más que organizaciones para alcanzar el poder. Sus éxitos electorales se logran cuando aciertan a constituirse en "intelectual colectivo", esto es, cuando conquistan y expresan las expectativas y afanes hegemónicos en una sociedad.

Cierto que no son el cauce exclusivo para participar o luchar en un sistema político. Los partidos políticos son las formas modernas, fruto de un largo proceso de ampliación de

\footnotetext{
${ }^{22}$ Cfr. M.A. MACCIOCCHI, Gramsci y la revolución en Occidente, Madrid: Siglo XXI, 1976; y Leonardo PAGGI, Antonio Gramsci e il moderno Principe, Roma, 1970.

${ }^{23}$ Cfr. Harvey KAYE, Los historiadores marxistas británicos, Prensas Universitarias de Zaragoza, 1989; y recordar la importancia de la revista Studi Storici, editada por el Instituto Gramsci, de amplia resonancia en los años sesenta y setenta del pasado siglo XX.
} 
la participación ciudadana en la vida pública conquistada a través de la lucha por el sufragio universal masculino primero y femenino después. Por eso no hay que olvidar los precedentes, como los clubs o sociedades patrióticas en el caso español, pero también otros cauces de lucha política como los sindicatos de clase -obrera o patronal, por supuesto-, las cooperativas y sobre todo el protagonismo de organizaciones como los nuevos movimientos sociales entre los que destacan los del feminismo, gay, ecologismo, pacifismo, etc...

Y es que la historia política debe tener en cuenta ante todo la historia del grupo social para contextualizar y articular el significado de las relaciones políticas entre grupos sociales, adversarios o afines. Es una vez más la historia social la que nos emerge como referente inexcusable para comprender esa parcela de la realidad cual es la política, sin que ésta derive en la segmentación politicista, porque, en el análisis de los aparatos ideológicos del Estado, son los procesos históricos en su globalidad social los contextos que explican esa determinación de actores políticos, de conflictos de clases y de ideologías en pugna por hacerse con la hegemonía cultural ${ }^{24}$.

\section{4.- Tendencias y métodos: individuos, comparaciones y memorias.}

La historia política también ha recibido nuevos impulso desde otras perspectivas metodológicas. Lógicamente no podían faltar quienes seguían la tradición liberal y la historicista que, en las sucesivas décadas del siglo XX, prolongaron su tarea rigurosa de crítica documental o sus historias descriptivas de las luchas políticas como conflictos entre individuos e ideas. Aportan una visión de la historia política como el ámbito donde se ejercita la libre racionalidad de los hombres, y por eso, en los años sesenta, frente a la especialización de la disciplina se rescató la dimensión moral y pública de la historia como práctica socialmente relevante. Esto implicaba un compromiso teórico marcado por el individualismo metodológico que sostiene que el individuo puede sobreponerse a las circunstancias sociales, económicas y geográficas para tomar decisiones y moldear su vida con arreglo a sus ideas. Por eso la historia política vista con esta perspectiva se centra sobre todo en el pensamiento y la acción de los individuos, con el convencimiento de que son los seres humanos, de uno en uno, los que

\footnotetext{
${ }^{24}$ Vid. K. LENK y F. NEUMANN, Teoría y sociología críticas de los partidos políticos, Barcelona,
} Anagrama, 1980. 
forjan sus destinos. Sin duda, este individualismo no era nuevo, pero ahora se reforzaba contra los paradigmas que propugnaba la historia social y se reforzaba con la búsqueda de los microfundamentos de los hechos colectivos ${ }^{25}$.

Semejantes postulados revitalizaron obviamente el género biográfico, que, por lo demás, no había dejado de ser una parcela bastante cultivada en esa historiografía cuyas raíces historicistas y románticas seguían presentes con bastante relevancia en medios académicos e intelectuales. Ahora, sin embargo, adquiría mayor relevancia porque la nueva realidad de los lanzamientos comerciales de las casas editoriales convertía en éxito social la cómoda reducción de los conflictos y explicaciones de un período a la biografía de un personaje. Así ocurrió con las biografías comparadas de Hitler y Stalin realizadas por Bullock porque, frente al estudio de los factores condicionantes de cada época y sistema político, es más digerible subrayar la contingencia de las vivencias personales. Además, el género biografía permitía soslayar el despliegue de un paradigma omnicomprensivo para instalarse en la cómoda perplejidad de las vicisitudes de un individuo. En España tenemos un ejemplo de rotundo éxito, la biografía del dictador Franco por Paul Preston, caso que reúne todas las virtudes de ese análisis de una época a través de la correspondiente catálisis biográfica, pero que igualmente deja al lector con la sensación de reducir el entramado social a las vaivenes de una sola voluntad.

La espectacular vuelta del sujeto esconde, por lo demás, diversas interpretaciones y posibilidades historiográficas. En todo caso, frente a la interpretación autónoma del espacio político como algo libre de los condicionantes socioeconómicos y de esos largos plazos de unas estructuras, no sobra recordar, aunque sea someramente, que ya en el siglo XIX fue Carlos Marx quien en su obra El 18 Brumario de Luis Bonaparte formuló la norma metodológica quizás más precisa y ajustada para el análisis histórico. Que "los hombres hacen su propia historia, pero no la hacen voluntariamente, no en circunstancias elegidas por uno mismo, sino en circunstancias halladas, dadas y transmitidas" 26 .

\footnotetext{
${ }^{25}$ G. HIMGELFARB, The New History and the Old. Critical Essays and Reappraisals, Harvard University Press, 1987; A.E. GALEOTTI, Individualle e colletivo. L' Individualismo politico metodologico nella teoria politica, Milán, Franco Angeli, 1988; y François DOSSE, "La Historia contemporánea en Francia", Historia Contemporánea, núm. 7, 1992, pp. 17-30.

${ }^{26}$ K. MARX, El 18 Brumario de Luis Bonaparte, Barcelona, Ariel, 1971, p. 11.
} 
En este sentido, hay que enunciar al menos las aportaciones que han supuesto para la historia política aquellas tendencias historiográficas que como la Alltagsgeschichte alemana y la microhistoria italiana han enseñado a desentrañar comportamientos y actitudes en los conflictos sociales. Ambas coinciden con la historia política y con el género biográfico en valorar en su justa medida la proximidad que se da el detalle, sin por ello dejar de lado las grandes cuestiones ${ }^{27}$. En definitiva, la historia política puede enriquecer el género biográfico y las correspondientes prosopografías, adoptando de la historia sociocultural el concepto de "espacio de experiencia" para comprender al individuo con referencia a unos caracteres medios y a sus particularidades, porque cada recorrido biográfico es único a partir de una experiencia sociopolítica y generacional común ${ }^{28}$.

En otro orden de cosas, la historia política también se ha renovado con las nuevas perspectivas sobre los procesos y actuaciones de masas aportados por la sociología histórica, una especialidad que ha irrumpido de nuevo desde el ámbito anglosajón con la pretensión de encontrar la fórmula científica definitiva para las ciencias sociales. Otra vez reaparecen los métodos de comparación analítica de grandes procesos y estructuras como mecanismos para determinar las causas macrosociales. En ese propósito ha coincidido desde marxistas de diferentes enfoques como Perry Anderson o Charles Tilly, hasta un sólido núcleo de sociólogos, norteamericanos y británicos, opuestos a los anacronismos o a la intemporalidad de la sociología clásica ${ }^{29}$. De las diversas estrategias de investigación utilizadas (modelos teóricos o historia comparada), el caso que mayor atención ha suscitado precisamente ha sido de historia política, el referido a la aparición y consolidación del Estado moderno dentro del amplio proceso de transformaciones sociales que lo han perfilado en los últimos diez siglos, tal y como hacen Charles Tilly o Michael Mann.

En efecto, tanto Tilly como Mann han subrayado que los procesos cruciales de cambio social han de entenderse como consecuencias no intencionales de acciones intencionales, esto es, como procesos básicamente ciegos que no responden a designio o

\footnotetext{
${ }^{27}$ G. LÉVI, "Les usages de la biographie", en Annales E.S.C., no 6, 1989, pp.1325-1336; la perspectiva de la sociología histórica, Peter LASLETT, "Biography as Historical Sociology", Theory and Sociely, 20, 1991, pp. 501-538.

${ }^{28}$ Es oportuno recordar la obra de Lawrence STONE, El pasado y el presente, México, FCE, 1986, en especial pp. 61-94, referidas a la prosopografía.

${ }^{29}$ Theda SKOCPOL, "Temas emergentes y estrategias recurrentes en sociología histórica", Historia Social, $n^{\circ} 10,1991$, pp. 101-134. De tales aspectos, ver Santos JULIÁ, Historia sociall sociología histórica, Madrid, Siglo XXI, 1989, sobre todo el cap. 4.
} 
plan alguno, pero resultan consecuencialmente de lo que hacen actores -individuos o colectivos- intencionales. Un planteamiento que no significa la vuelta a la historia estructural, con actores portadores de unos designios estructurales, sino que tratan de quitar el monopolio explicativo a las intenciones sobre la acción, porque, frente a los esquematismos teleológicos, reiteran el carácter no reductible a intencionalidad de las transformaciones históricas ${ }^{30}$.

No es éste el lugar para detallar las aportaciones de Tilly o Michel Mann. Baste con resumir sus postulados teóricos e historiográficos con el calificativo que M. Mann ha usado para sí mismo, el de un "weberismo marxistizado" que, desde luego, ha vuelto a dar renovados impulsos a la historia política como parte de las ciencias sociales, por más que se constaten aspectos criticables ${ }^{31}$. Son autores que, por lo demás, ha potenciado la lógica del método comparativo, aplicado ya en el siglo XIX por cientificos sociales como Alexis de Tocqueville o Marx, luego por el cofundador de los Annales, Marc Bloch ${ }^{32}$ y que se hizo ya especialidad diferenciada cuando en los años cincuenta del siglo XX se fundó la revista Comparative Studies in Society and History en los Estados Unidos. Este método ha dado notables resultados, como las obras citadas antes y la muy destacable de Barrington Morre $^{33}$. Las discusiones teóricas sobre la utilización del método comparativo en historia ${ }^{34}$, en plena crisis del análisis estructural, han obligado a revisar algunos aspectos del mismo, en lo que ha destacado la historiografía norteamericana de nuevo ${ }^{35}$. Parten del hecho de que ningún trabajo científico, por muy limitado y monográfico que sea, puede prescindir totalmente del recurso al método comparativo puesto que resulta imposible la introducción de

\footnotetext{
${ }^{30}$ Michael MANN, Las fuentes del poder social, II. El desarrollo de las clases y los Estados nacionales, 1760-1914, Madrid, Alianza, 1997; y de Charles TILLY, Grandes estructuras, procesos amplios, comparaciones enormes, Madrid: Alianza, 1991, p. 30; también Coerción, capital y los Estados europeos, 990-1990, Madrid, Alianza, 1992; y además, Las revoluciones europeas. 1492-1992, Barcelona, Crítica, 1995. Para la obra de Tilly, ver el dossier de Historia Social, n 15, 1993, pp. 67-136, con participación del propio Tilly.

${ }^{31}$ Michael MANN, "El poder autónomo del Estado: sus orígenes, mecanismos y resultados", Zona Abierta, $\mathrm{n}^{\circ}$ 57/58, 1991, pp. 15-49 (ed. orig. de 1984); y sobre todo su obra antes ya citada: Las fuentes del poder social, Madrid, Alianza, t. I, 1991, y t. II, 1997.

${ }^{32}$ M. BLOCH, "Pour une histoire comparée des societés européenes", en Revue de Synthése Historique, 1928. También en "Comparaison", en Revue de Synthése Historique, 1930, t.LXIX.

${ }^{33}$ B. MOORE, Los orígenes de la dictadura y de la socialdemocracia, Barcelona, Península, 1976.

${ }^{34}$ SMELSER "Comparative Methods"; LIJPHART, L. "Comparative Politics and the Comparative Method", en American Political Science Review, 1971. HOPKINS Y WALLERSTEIN, "Comparative study of National Societies", y ZELDITCH, M. "Intelligible Comparison", en Comparative Methodos in Sociology. Berkeley, University of California Press, 1971.

${ }^{35}$ E.A. HAMMEL, "The Comparative Method in Anthropological Perspective"; V.E. BONNELL, "The Uses of Thory, Concepts and Comparison in Sociology"; T. SKOCPOL y M. SOMERS, "The Uses of Comparative History in Macrosocial Inquiry", en Comparative Studies in Society and History, n1 22, 1980, pp. 145-197.
} 
fenómenos nuevos sin compararlos con los ya conocidos ${ }^{36}$. Por eso, el método comparativo no debe suponer la pérdida de precisión en lo individual y propio de cada objeto de estudio, ni debe reducirse a buscar sólo las similitudes sino también las diferencias, como a veces pareciera que ocurre en la historiografía política y económica española, tratando de normalizar el pasado comparando con tres o cuatro países europeos, para olvidar que existen dramáticas diferencias, como una dictadura de cuarenta años ${ }^{37}$.

Además de estas corrientes, en el último tercio del siglo XX se consolidó una nueva perspectiva en la historia política representada por dos autores franceses, Réné Rémond y F. Bédarida, quienes, sin estar en la órbita de los Annales, han consolidado la revista Vingtiéme Siécle, para rehabilitar la clásica historiografía enraizada en Langlois y Seignobos, aunque depurada por los nuevos derroteros interdisciplinares de la ciencia histórica. Ya se ha enunciado en páginas anteriores el planteamiento de Rémond al perfilar la "nueva historia política" 38 . Al hilo de estas aportaciones se encadenaron nuevas reflexiones historiográficas, como las relativas a las causas y motivaciones de la acción política, a los mecanismos e intenciones que subyacen bajo la retórica política y al significado de los individuos en las estrategias de poder. En este punto es donde aparece la prosopografía para "hacer inteligible la acción política" y explicar los cambios ideológicos y culturales, identificar la realidad social y describir y analizar con precisión la estructura de la sociedad ${ }^{39}$. Semejantes objetivos historiográficos han hecho

\footnotetext{
${ }^{36}$ W. KULA, Problemas y métodos de la historia económica. Barcelona, Península, 1973, p. 571.

${ }^{37}$ La utilización instrumental del método comparativo ha sido puesta en entredicho por la antropología al comparar sociedades (ver R. ROWLAND, Antropología, Historia e Diferença. Alguns aspectos. Lisboa: Afrontamento, 1987). Además hay que recordar casos graves de anacronismos, como los perpetrados por Spengler, Toynbee o Rostow ( ver la crítica de Lucien FEBVRE, Combates por la Historia, Barcelona, Ariel, 1970, pp. 183-217)

${ }^{38}$ Conviene recordar obras citadas en notas anteriores como las de R. RÉMOND, Pour une histoire politigue, Paris, Ed. du Seuil, 1988; previo fue J. JULLIARD, "La política", en J. LE GOFF y P. NORA, Hacer la historia, Barcelona, Laia, 1979, vol. II, pp. 237-357 (ed. orig. de 1974). También J.F. SIRINELLI, "E] retorno de lo político", en Historia Contemporánea, no 9, 1993, pp. 25-35; y G. NOIRIEL "Une histoire sociale de la politique est-elle possible?", en Vingtiéme siécle, $n^{o} 24,1989$. Aportaciones españolas al respecto, la de $\mathrm{M}^{\mathrm{a}}$ Cruz MINA: "En tomo a la nueva historia política francesa", Historia Contemporánea, no 9, 1993, pp. 59-91, y la de Teresa CARNERO, "La renovación de la historia política", en A. MORALES y M. ESTEBAN DE VEGA (eds.): La historia contemporánea en España, Universidad de Salamanca, Salamanca, 1996.

${ }^{39}$ Ver cita de L. STONE, "Prosopografía", en El pasado y el presente, México, FCE, 1986, pp. 61-94.
} 
de la prosopografía una parcela de investigación no sólo de la historia política, sino especialmente de la historia social ${ }^{40}$.

Otra parcela de investigación con notorias realizaciones dentro de estas nuevas perspectivas de la historia política es la referida a las identidades como referente movilizador de la acción política, individual y colectiva; sobre todo, el estudio de las identidades nacionales. La producción en este campo ha alcanzado tal cantidad de aportaciones que exigiría un tratado específico sólo este ámbito del análisis político, que, por lo demás, se encuentra íntimamente relacionado con la historia cultural y social. Por eso el desarrollo de los estudios sobre los nacionalismos ya es un ámbito de la historiografía que también ha demostrado las potencialidades de la interdisciplinariedad pues a su conocimiento han contribuido politólogos, sociólogos, antropólogos e historiadores.

Junto al nacionalismo, la historia del tiempo presente y, por tanto, de la memoria colectiva que marca el comportamiento político constituye otro ámbito de especial innovación y de extraordinario auge. transformación de la experiencia de los individuos y de los distintos grupos sociales y colectivos nacionales. En efecto, la llamada memoria histórica, tan debatida desde distintas perspectivas, no es sólo el recuerdo del pasado que se inculca desde las diferentes identidades culturales sino también los soportes de información del presente que permitirán en el futuro elaborar la historia apoyándose en la tecnología de la información como soporte. En todo caso, el estudio de la historia de la memoria colectiva supone cierta ruptura epistemológica en la historiografía del presente porque los "lugares de la memoria" 41 se convierten en eslabones imprescindibles para una lectura completa de la misma historia como realidad social y como disciplina científica ${ }^{42}$. Se trata de una prolongación del mismo objeto de estudio, de su definición y de sus límites cronológicos, pues integra tanto el análisis de los hechos como el recuerdo de los mismos, de manera que los hechos, analizados con la historia de su propia memoria, pierden su singularidad radical para pasar a ser parte de una diacronía que se prolonga hasta el presente.

\footnotetext{
${ }^{40}$ Ver para España, entre otros, los trabajos de Pedro CARASA, dir., Elites castellanas de la Restauración. Una aproximación al poder político en Castilla, Salamanca, Junta de Castilla y León, 2 vols., 1997.

${ }^{41}$ Pierre P. NORA, Les lieux de mémoire, Paris: Gallimard, 1992, 4 vols.

${ }^{42}$ Ver el cap. 3 de "La historia como memoria colectiva" de Peter BURKE, Formas de historia cultural, Madrid, Alianza, 2000.
} 


\section{5.- Cuestiones abiertas}

Por lo demás, el debate sobre la nueva historia política no está concluido pues bajo esta denominación se encuentran estudios tan dispares como los que van desde el análisis de la élite de los gobernantes a los que prolongan la historia de las instituciones y de la administración, o aquellos otros que abordan los mecanismos de adquisición y organización del poder, o, por ejemplo, proponen rescatar la historia militar como pieza básica... En este orden de cosas, la historia de las ideas adquiere cada vez más importancia para el análisis no sólo de la historia política, sino de la historia en general porque ensambla el pensamiento con la acción política para aprehender esa "unidad cultural más amplia" que es la sociedad ${ }^{43}$.

Es importante subrayar en este punto las aportaciones de la historia de los conceptos de R. Koselleck, quien, sin confundirla con la historia de la lengua, le asigna como objeto de estudio la terminología sociopolítica relevante de un período. El concepto constituye, por supuesto, algo más que la palabra: encierra significados sociopolíticos no sólo como indicadores del contexto sino como elementos constructores dentro del contexto. Así, la historia de los conceptos parte de una premisa lingüística: sólo se puede estudiar la sociedad de una época después de analizar los conceptos usados en esa realidad social. La historia se plasma en conceptos y sólo puede ser entendida tras analizar los conceptos, y así las nuevas realidades históricas sólo pueden expresarse mediante conceptos nuevos o conceptos antiguos que cambian de significado. El propio subtítulo de la obra R. Koselleck, para una semántica del tiempo histórico, demuestra que los hechos históricos se expresan en una mediación lingüística y conceptual entre el documento y la representación ${ }^{44}$. La prioridad reclamada para la reflexión lingüística en la investigación del pasado no sólo es una exigencia metodológica, sino también un compromiso político con el presente para conjugar tanto los factores de articulación lingüística, como los factores extralingüísticos.

La conclusión al respecto es evidente, que la historia política, la historia de las ideas, la historia intelectual y la historia de la memoria están inextricablemente unidas a la historia social. Esto significa que no sólo se debe analizar la política desde los correspondiente soportes sociológicos, sino que metodológicamente hay que aceptar motivaciones no siempre

\footnotetext{
${ }^{43}$ N.R. STROMBERG, Historia intelectual europea desde 1789, Madrid, Alianza,1990.

${ }^{44}$ R. KOSELLECK, Futuro Pasado. Para una semántica del tiempo histórico, Barcelona, Paidós, 1993.
} 
aprehensibles racionalmente pues proceden más de las emociones y de los sentimientos fabricados culturalmente ${ }^{45}$. Por eso, quizás se pueda plantar como conclusión que la historia política no puede seguir constreñida por el marco de los Estados nacionales porque tanto lo regional como lo internacional constituyen ámbitos de estudio imprescindibles. En definitiva, cualquier espacio político, sea nacional, local o internacional, exige en sus investigaciones el conocimiento del contexto cultural, religioso, tecnológico, económico tanto de los individuos como de los colectivos y, por supuesto, de las instituciones gobernantes, así como de los correspondientes discursos e ideologías.

En definitiva, conviene distinguir entre explicación de las instituciones y explicación del comportamiento. Lo primero es cosa de las ciencias sociales. Lo segundo de todas las ciencias. Y en ambas empresas, las ciencias biológicas son cada vez más importantes, hecho que también debemos tener presente pensando en el futuro de las investigaciones históricas. Las instituciones son obra de las gentes, y responden a las características de las personas, en último término con base biológica, pero de un modo complejo, porque el comportamiento individual, claro está, es también el resultado de las instituciones y de las características de los individuos. Ahora bien, llegados a este punto se abren unas perspectivas que ya son inéditas en nuestra disciplina, la de las aportaciones del conocimiento de las ciencias biológicas para las explicaciones sociológicas. Estamos en el umbral probablemente de una nueva era de ensamblaje entre la clásica división de ciencias de la naturaleza y ciencias sociales, todas igualmente humanas.

${ }^{45}$ Cfr. Peter BURKE, Formas de historia cultural, , Madrid,Alianza, 2000. 

